\title{
Research and Implications on OECD Governments' Procurement Policy to Promote Technology Innovation
}

\author{
Zhao Yu \\ School of Public Finance and Tax, Central University of Finance and Economics, Beijing, China
}

Email address:

zhaooooyu@163.com

\section{To cite this article:}

Zhao Yu. Research and Implications on OECD Governments' Procurement Policy to Promote Technology Innovation. International Journal of Sustainability Management and Information Technologies. Vol. 5, No. 1, 2019, pp. 15-22. doi: 10.11648/j.ijsmit.20190501.13

Received: January 24, 2019; Accepted: March 26, 2019; Published: April 18, 2019

\begin{abstract}
Government procurement has great advantages in reducing the uncertainty of innovation, expanding the demand for innovative products, making up for the positive externalities of innovation, and improving the quality of public services, which can directly promote innovation. The use of government procurement to promote innovation is a common practice in many OECD countries. These countries have developed legal or policy tools to ensure that government procurement fully promotes innovation, and integrate innovation goals with other policy goals to better address social challenges. However, in recent years, China has not attached importance to the role of government procurement in promoting innovation, which is not conducive to the development of innovation. By learning from the experience of OECD countries, China should restore and improve the policy design to make it more operable and integrate the goal of promoting innovation into other social goals.
\end{abstract}

Keywords: Government Procurement, Independent Innovation, OECD, Policy Implications

\section{Instruction}

Manufacturing is the main body of the national economy and an important guarantee for social and economic development, which directly reflects the productivity level of a country. Since the reform and opening up, the overall scale of China's manufacturing industry has expanded continuously, and now it has been playing a leading place in the world, which has further strengthened its comprehensive national power and international competitiveness. However, China's manufacturing industry is still in a state of "big but not strong", especially in the high-end equipment manufacturing industry, which still has a large gap compared with the top level in the world [1]. China is in a critical period to renew the driving forces for economy, but some core technologies are controlled by other countries. In order to breakthrough the barriers, it is urgent to strengthen confidence, continuously implement innovation-driven strategies, and improve independent innovation capability [2].

In the field of innovation policy, governments in the world usually focus on the supply side, such as providing research and development subsidies, tax reductions, and financial loan concessions to support innovative enterprises and create an environment conducive to innovation. In recent years, making "demand side policy" to support innovation has become a tendency [3]. Governments around the world have gradually realized that when the demands for new technologies and new products emerge, the driving power for innovation of enterprises will increase greatly. As the largest consumer in China, China government has an extremely strong ability to create and shape the market conditions, and profoundly influences the demands at the national or regional level. Therefore, an effective policy to support innovation must balance both supply and demand. Combining technological development with government procurement is a very beneficial way to push technological innovation.

Unfortunately, the current political guidance documents on government procurement to promote innovation are still in a state of "failed". In November 2011, the General Office of the State Council issued a notice to break the linkage between innovation policies and the government procurement preferences, requesting the local governments and relevant departments to stop implementing the measures in the normative documents that support the linkage between innovation policies and government procurement preferences from December 1, 2011. So far, the practice of relying on government procurement to promote independent innovation has fallen apart. In fact, the use of government procurement is 
an important measure in developed countries such as Europe and the United States, to promote innovation and has received more and more support on the political level. A number of documents issued by the European Commission and the OECD have well responded to this appeal. The "decoupling" of government procurement from innovation policies in China suggests an insufficient understanding of China on the positive role of this policy, which is harmful to the technological innovation, leads to severe overcapacity in China, and finally holds China down at the low end of the global value chain in the international division of labor. Therefore, learning good practical experiences from foreign countries, improving the sense of public sectors to understand the benefit to combine government procurement and innovation promotional policy, and thus doing a proper top-level design, is of great significance to implement China's innovation-driven strategies and enhance overall national strength.

\section{The Necessity of Government Procurement to Promote Innovation}

\subsection{Reducing Innovation Uncertainty}

Uncertainty is both a feature of innovation and also an obstacle to limit the process of innovation. Enterprises always face a series of risks in the process of $R \& D$ and innovation, and these risks are much higher than other activities in the companies. Many researches have shown that the rate of failure in technological innovation is very high. When researching the development of different products on chemical, pharmaceutical, petroleum and electronic industries, Mansfield (1981) found that only about $20 \%$ of these projects had finally achieved successful commercialization [4].

First, R\&D is a complex, long-term, and challenging process, with high risks of failure at each phase. A technology that generates products out of scientific theories requires multiple trials. In the practice, $R \& D$ companies may find it difficult to make accurate predictions about innovative technologies, or they may be limited by their own technical level and equipment, and the technology can not be directly applied in production due to immaturity. Second, even if the technology is successfully transformed into actual production activities, there is still much more uncertainty. Innovation requires a process to adapt to the market. Whether the innovative products can be accepted by the market and when they can be accepted needs to be tested in the market. It is possible that even if the technology development of the enterprise is successful and the production is stable, but when the new products are put into the market, they cannot cover the cost because they are not accepted by the consumers. Enterprises always tend to avoid risks, and the uncertainty of innovation will absolutely constraints their innovation investment. Enterprises always tend to avoid risks, so the uncertainty of innovation will restrict enterprises ' investment in innovation activities.

Government procurement is to use the "visible hand" to control "invisible hands", which means to expand the market demand for independent innovation products through appropriate procurement policies, thus greatly reducing the market-related uncertainties for independent innovation. Through this procurement method, the government can also support innovative enterprises to carry out research and development activities through pre-commercial procurement (PCP) or forward commitment procurement (FCP), thereby reducing the uncertainty of technological innovation in the early phase. In this circumstance, through consultation with potential suppliers, the government can designate a target product in advance, propose the specific product functional requirements or technical parameters, seek enterprises to supply innovative solutions, and guide the development direction of the technological innovation industry.

\subsection{Expanding Demands for Innovation}

For R\&D and innovative companies, the demand pull is particularly important before commercialization and in the early stage of marketization. From the perspective of market economy, demand-driven technological innovation is more likely to succeed than supply-driven technological breakthroughs. Economist Schumpeter pointed out that "production is always made to meet demands, because demands are the ultimate goal of production [5]." American economist Michael Porter states in his book "National Competitiveness" that domestic demand has played a key role to drive innovation in the country [6]. And the advanced and challenging domestic demand is an important factor in determining whether the region is attractive and have good economic performance. The essence of enterprise technology innovation is demand-oriented innovation, and market demands are playing a decisive role to guide what enterprises need to produce.

Based on market demand, the scale of demand is also highlighted. Innovation incentives are usually proportional to market size, because producers can achieve scale production more efficiently with a larger market demand, and then generate greater expected profit, which will motivate more incentive for innovation. The fixed cost of technological innovation is very high. In order to make the technological innovation profitable for R\&D enterprises, they must share the huge fixed cost with a considerable scale of market demand.

In the past ten years, the scope of government procurement in China has gradually expanded from products to services and engineering projects, and the scale of procurement has achieved rapid growth, especially in recent years. In 2003, when the "Government Procurement Law" was implemented, the government procurement volume in China was only 165.94 billion RMB, accounting for $6.7 \%$ and $1.4 \%$ of the fiscal expenditure and GDP of the year. However, in 2017, the national government procurement scale has exceeded 3.21 trillion RMB, accounting for $12.2 \%$ and $3.9 \%$ of the national fiscal expenditure and GDP respectively, which has achieved a continuous growth both in scale and in the ratios of fiscal expenditure and GDP.

With the continuous expansion of the scope of government 
procurement in China, it is expected that the proportion of China's procurement expenditure will continue to increase in the future. Considering that government procurement has accounted for such a large rate in total demands, it is strong enough to play a guiding role in market demands. If government procurement is inclined to innovative products, it will create a stable leading market demand for $R \& D$ enterprises, and then transmit the tendency to different consumer groups, which will positively promote technology innovation and industrialization of innovative products [7]. In addition, the forward commitment procurement for samples and other phase results as well as the technical projects in the progress of technological innovation will effectively motivate the reinvestment and strengthen the confidence of $R \& D$ enterprises in the development for high-tech products, promote the updated technical standards for new products and enhance the technological innovation capability and market competitiveness of domestic high-tech enterprises.

\subsection{Supplementing the Externality of Innovation}

Innovation has externality and there is a "spillover effect" [8]. Innovation is essentially the process of creating new technological knowledge. The results of innovation, no matter new products or new technologies, both of them include new knowledge. The innovation outputs are only partially exclusive. If there is no intellectual property protection, when the innovative products enter the market, other enterprises can copy or follow the innovative product through legal or illegal ways and take the "free rider" to enter the market. For R\&D companies, innovation is developed based on enormous cost and resources, but the cost of replicating or modifying innovations by other companies can be very low. This will cause the incomes for the R\&D enterprise to be lessened, and unequal to the actual social benefit. The high investment cannot be covered, the market cannot provide sufficient R\&D investment, and as a result, the virtuous circle of $R \& D$ innovation will be broken. Therefore, innovative products need to be fostered by the government in corresponding markets [9]. The government's active support for independent innovation through procurement will play a demonstration role to enhance the popularity and influence of independent brands, create a good policy environment for technological innovation to stimulate the development of innovation, and guide other social entities to support independent innovation and form the consumption behaviors to respect innovation.

\subsection{Achieving Public Policy Goals and Improving Service Quality}

Purchasing innovative products and services is a necessary requirement to update government functions and improve the quality of public services. Procurement policies for innovation are often associated with certain policy goals, such as sustainable development, improving energy efficiency and promoting the development of small and medium enterprises. These policy goals can be effectively achieved through procurement for innovation. Usually, policy goals are built based on social needs, which reinforce the opinion that government procurement can be used as a market incentive tool because it can transform social needs into specific market needs, and it exactly caters to the political needs for good governance. The government's choice to pay more cost to purchases innovative products has played a demonstrating role for the market, which will accelerate the cost recovery of R\&D enterprises, and increase reinvestment of enterprises. As a result, it will significantly enhance the technological innovation capability of a country or region. Government procurement can successfully transform social demands into effective market demands, which plays a leading role to make innovative products meet new social demands, provide better public service, and promote the government functions to achieve better performance.

\section{Awareness of the Controversy over the Government Procurement for Independent Innovation in China}

In the third generation of innovation policy system, government procurement has been highly valued by the United States, the European Union and other countries and has become an important policy tool to support enterprise innovation and promote the development of high-tech industries. Since November 2009, the United States, the European Union, Japan, and South Korea have expressed their so-called serious concerns about China's "Notice on the Implementation of National Independent Innovation Products in 2009", which they though as discrimination against foreign investment. And they also thought the limitation of registered trademarks had violated the non-discrimination principle of the WTO Agreement and the implementation of preferential government procurement for independent innovation products had violated China's commitment to oppose trade protectionism and promote open and fair government procurement policies.

\subsection{China's Government Procurement Policy System to Promote Innovation}

At the end of 2005, in the National Medium- and Long-Term Plan for Science and Technology Development (2006-2020), it was proposed to "implement government procurement to promote independent innovation". In 2006, the State Council issued the "Notice on implementing a number of supporting policies for the National Medium- and Long-Term Science and Technology Development Plan (2006-2020)", which had played a guiding role in the formulation of laws and regulations for the promotion of innovation though government procurement. In order to implement the above-mentioned supporting policies, the Ministry of Finance, the Ministry of Science and Technology, the National Development and Reform Commission and other relevant departments have formulated and issued the "Measures for the Administration of Government Procurement Budgets for Independent Innovation Products", 
the "Measures for the Evaluation of Government Procurement of Independent Innovation Products", the "Measures for the Management of Government Procurement Contracts for Independent Innovation Products", the "Opinions on Implementing the Government Procurement Policy for Promoting Independent Innovation" and the "Administrative Measures for Government Procurement of Imported Products", which have initially formed a policy framework for government procurement incentives for independent innovation. Based on this, Beijing, Shanghai, Guangdong and other provinces and cities have also improved the policy system of government procurement incentives for independent innovation, and made further explorations on the establishment of the government procurement system for independent innovation product, the certification for independent innovation product, the innovative methods for procurement, the optimization for standards of procurement evaluation, the priority for purchase of domestic equipment in major construction projects, the innovation of procurement mechanisms for independent innovation products, and incentives for the procurement of innovative products from small and medium enterprises. Some local governments began to implement policies such as purchasing newly emerging products, designating innovative suppliers, purchasing the demonstrating products and so on.

However, this series of policies has triggered strong dissatisfaction among countries such as European countries and the United States. The European Union Chamber of Commerce in China, the American Chamber of Commerce in China, the National Committee of the US-China Business Council and other organizations have continuously expressed their concerns and worries about China's implementation of these policies through releasing investigation reports and holding meetings and dialogues with Chinese government. They thought of the policies as discrimination and unfair treatment for foreign companies, including the limitation of intellectual property rights and registered trademarks. They also thought it had violated the non-discrimination principle of the WTO and the implementation of preferential government procurement for independent innovation products had violated China's commitment to oppose trade protectionism and promote open and fair government procurement policies. Under this pressure, China canceled the policy of government procurement to promote independent innovation in 2011, which directly led to the failure to implement policies of purchasing newly emerging products and designating suppliers for innovative products and services.

\subsection{Analysis of the Causes of the Controversy}

From the practice of government procurement and innovation policy, purchasing domestic products, strategically fostering high-tech and emerging industries, and supporting small and medium enterprises are actually common strategies in developed countries to promote innovation though government procurement. The supportive policies on procurement to promote innovation in China or similar polices can also be found in developed countries. Why China was questioned and opposed for implementing these polices for promotion of independent innovation? The main reasons are as follows:

First, the policy definition is too narrow, and there are a lot of sensitive words such as "independent", "native", "trademark and brand recommendation", and "substitution for imported products", which do not conform to international rules. In 2010, the National Committee of US-China Trade pointed out in the "International Best Practices for Innovation: Suggestion on China's Innovation Incentives Policies" that there were many preferential policies for independent innovation products in China's laws, regulations and policies. They listed 21 preferential policies issued by local government about the management measures for purchasing independent innovation products, and proposed that 16 of them explicitly mentioned substitution for import, which could be seen as discrimination against foreign enterprises. Although some countries also adopt government procurement policies to promote innovation, they do not reply on the intellectual property rights and trademarks as the basis for government procurement projects.

Second, China don't have enough experience in international negotiations around innovation policy, and is often unprepared when facing foreign criticism. The United States is one of the earliest parties to join the Government Procurement Agreement (GPA), but it has never given up the legal system such as the Purchase of American Products Act. In February 2009, the US\$787 billion economic stimulus scheme signed by US President Barack Obama included the famous "purchase of American products" clause [10]. China has not yet joined the GPA, and it is actually unreasonable to use the WTO rules to blame Chinese actions. Even if China joins the GPA, it can also follow international practices to circumvent the limitation through domestic legislation.

Western countries were putting pressure on China's policies on independent innovation and government procurement, exactly when China was in the critical negotiations to join the "Government Procurement Agreement", which has thus amplified the influence of the events. However, as a macro-policy tool, government procurement has been proven by both theory and practice as a good strategy to reduce innovation risks and plays a better role than R\&D subsidies in stimulating innovation [11]. Therefore, government procurement is indispensable in the innovation policy system for promoting China's innovation-driven strategies.

\section{Experience from OECD Countries}

Among OECD member states, public procurement is increasingly recognized as a potential strategic tool and policy lever to achieve government policy goals, such as supporting for innovation, supporting for development of small and medium enterprises, and supporting for sustainable green growth.

\subsection{Government Procurement Is a Popular Way to Promote Innovation}

To date, OECD member countries have made different 
progress in using various policies and strategic tools to encourage and develop innovation. Among them, the use of government procurement to promote innovation has been included into the innovation strategies of many countries or regions. According to a survey released by OECD in 2017 against 28 member countries and 7 non-member countries, about half of the countries have taken specific measures, and $26 \%$ of them have developed stand-alone action plans. And $24 \%$ of the countries have included innovation procurement into national procurement strategies ${ }^{12}$. See Table 1 and Table 2 for details.

Table 1. Country example that have developed stand-alone action plans.

\begin{tabular}{|c|c|}
\hline Austria & $\begin{array}{l}\text { Austria established the "Austrian Action Plan on Public Procurement Promoting Innovation (PPPI)" in } 2012 \text { as the extension of "Austrian } \\
\text { Strategy for Research, Technology and Innovation RTI" in 2011. The RTI strategy used public procurement as a lever to develop } \\
\text { "systematic modern policies on research, technology and innovation". The PPPI Action Plan provides a detailed overview on how the } \\
\text { leverage affects (such as measures, resources, and responsibilities) are achieved. At present, all the above policies are in good progress. }\end{array}$ \\
\hline Canada & $\begin{array}{l}\text { The Canadian federal government has developed an economic action plan, part of which is to "Build in Canada Innovation Program" } \\
\text { (BCIP). The Canadian innovation strategy, titled with "Seizing Canada's Moment", is supervised by the Canadian Ministry of Innovation, } \\
\text { Science and Economic Development. }\end{array}$ \\
\hline Denmark & $\begin{array}{l}\text { The innovation procurement framework is part of the national procurement strategy. In October 2013, the Danish government launched the } \\
\text { "Smart Public Procurement Strategy". }\end{array}$ \\
\hline France & $\begin{array}{l}\text { As a demand side tool, the French procurement framework for innovation is part of the innovation strategy. The main goal is to support the } \\
\text { development of innovative small and medium enterprises, to fund their innovation and development, and to provide them with opportunities } \\
\text { to enter new markets. }\end{array}$ \\
\hline Mexico & $\begin{array}{l}\text { In 2013, President Enrique Pena Nieto ordered the Ministry of Economic Affairs to develop a plan to promote innovation through public } \\
\text { procurement. }\end{array}$ \\
\hline Netherlands & The Netherlands has developed an independent action plan for procurement for innovation: "Innovatiegericht Inkopen". \\
\hline Turkey & $\begin{array}{l}\text { "Through public procurement to carry out technology development and domestic production plans "is one of the } 25 \text { major transformational } \\
\text { plans within the framework of the Tenth National Development Plan (2014-2018). }\end{array}$ \\
\hline The U.S. & $\begin{array}{l}\text { In 2010, the US Office of Management and Budget released an independent action plan for procurement for innovation called "the } 25 \\
\text { Implementation Plans to Reform Federal Information Technology Management". }\end{array}$ \\
\hline Russia & $\begin{array}{l}\text { The Russian Federation has formulated requirements for procurement for innovation in the laws, including the obligation to purchase } \\
\text { innovative products (in percentage terms). }\end{array}$ \\
\hline
\end{tabular}

Source: Country responses to OECD (2017), OECD Survey on Strategic Procurement for innovation 2015 in Public Procurement for Innovation: Good Practices and Strategies, Annex C, OECD Publishing, Paris.

Table 2. Country examples that have made general action plans as a component of other strategies.

\begin{tabular}{|c|c|}
\hline New Zealand & $\begin{array}{l}\text { ew Zealand has made a public procurement policy that promotes innovation. This policy framework provides a flexible and beneficial } \\
\text { vironment for generating new and improved solutions. }\end{array}$ \\
\hline Portugal & $\begin{array}{l}\text { Portugal does not have a specific strategic framework for procurement for innovation, nor does it have an independent procurement action } \\
\text { plan for innovation. However, Portugal's general legal system supports procurement for innovation and has set the scope of policy for } \\
\text { innovation procurement. Such as the Public Contract Law (2008). }\end{array}$ \\
\hline Spain & The Spanish Innovation Procurement Action Plan is part of the overall national innovation strategy and part of the procurement strategy. \\
\hline Sweden & $\begin{array}{l}\text { Sweden does not have a specific innovation procurement action plan, but instead it has incorporates procurement for innovation into the } \\
\text { Swedish innovation strategy (2012). }\end{array}$ \\
\hline The UK & The UK Small Business Research Program (SBRI) is the primary tool for promoting procurement for innovation. \\
\hline Colombia & $\begin{array}{l}\text { The Colombian National Development Plan (2014-2018) defines innovation procurement as a comprehensive strategy that covers different } \\
\text { fields, with the goal of creating higher economic and social values and creating better conditions for the development of business activities. }\end{array}$ \\
\hline Lithuania & $\begin{array}{l}\text { Currently Lithuania has paid special attention to the development for demand side measures. Although the country does not have an action } \\
\text { plan specifically for innovation procurement, it is part of the Lithuanian Innovation and Development Plan 2014-2020. }\end{array}$ \\
\hline Malta & $\begin{array}{l}\text { Malta has limited experience in innovation procurement and it does not have an independent policy for innovation procurement. However, } \\
\text { the existing procurement structure does allow procurement for innovation and there are some examples of applications of innovation } \\
\text { procurement. }\end{array}$ \\
\hline
\end{tabular}

Source: Country responses to OECD (2017), "OECD Survey on Strategic Procurement for innovation 2015 in Public Procurement for Innovation: Good Practices and Strategies, Annex C, OECD Publishing, Paris.

The lack of independent strategies or action plans for innovation procurement does not mean the countries have no initiatives related to innovation procurement. Although half of the countries under the survey did not specifically develop procurement action plans for innovation at the national level, nearly $80 \%$ of countries have adopted at least one or more specific actions to support innovation procurement. Some countries (such as Chile, the Czech Republic, Cyprus and Serbia) have provided examples of good practice but have no identified effective action plans.

\subsection{Different Policy Tools to Support Innovation Procurement}

In general, OECD countries' tools to support innovation procurement can be divided into the following categories: (a) policy tools such as overall strategy, legal framework targets, guidelines, and policy documents; (b) programs with the targets to achieve a policy goal; (c) financial tools, including monetary incentives for innovation procurement or special funds for innovative practices; (d) independent cases, one-time procurement projects. Some countries have adopted 
a variety of policy tools, which are the most common tools to support innovation procurement. These tools can be used in different forms, such as becoming part of the legal framework, developing targets for innovation procurement, issuing guidelines or regulations, or developing high-level strategies to support innovation procurement. Comprehensive programs at the national level are the second largest tools to support strategic procurement for innovation, but not all of the programs mentioned are aimed only at innovation procurement. Most programs have different focuses, such as general procurement for intelligent products, or focus on R\&D or departmental characteristics that have included innovation procurement as a factor. Financial tools are the third type to support strategic procurement for innovation. In most cases, there is a specific pool of funds special for procurement for innovation. Countries such as Austria, Denmark, Greece, and Spain have developed measures to provide financial support for innovation procurement.

\subsection{Targets and Results of Innovation Procurement}

Why countries choose innovation-oriented procurement rather than traditional procurement, and how can they achieve the goals to create better and favorable conditions and environments for innovation? Most countries believe that through procurement to promote innovation can address social challenges, which are often relevant to specific demands or requests. The reasons for implementing innovation procurement can be divided into the following categories: (a) Most countries under the survey emphasize that the demands for some products or services cannot be met, so specific new innovative products or services are needed, rather than the improved goods or services. (b) To improve the performance of existing products or services, such as lowering the total cost, improving energy efficiency and reducing risks; (c) To achieve overall strategy or high-level goals, such as increasing knowledge accumulation, raising awareness, and supporting innovative small and medium enterprises, which is developed as an independent policy goal, not just to meet specific needs; (d) Another reason is related to the solutions provided by the supplier. If the supplier can propose a better plan than the buyer has expected, the recommendation for improved solution will promote procurement for innovation.

According to the results of the report on Good Practice Cases, innovation procurement has basically achieved the desired goals. In most cases, innovation procurement has increased efficiency (16\%) and users' satisfaction (17\%), and the improvement on efficiency and effectiveness are mainly achieved though energy savings. In $13 \%$ of good practice cases, innovation procurement has improved services, such as street lighting improvements. Reliability and accessibility has been improved in approximately $10 \%$ of the cases, in which the services are more accessible through the use of information technology systems. In other cases, responsiveness (the ability to respond to different users' needs or opinions) has been increased.

\subsection{Combination of Innovation with Other Policy Goals}

In general, the first goal of government procurement is to purchase goods and services for the public sector based on the "good value for money" standard. According to strategic priorities, more and more secondary goals are included into policy considerations such as sustainability, innovation, and support for small and medium enterprises. The combination of secondary policy goals can help the public sectors to avoid unnecessary duplication and promote inclusive growth through synergy effect.

(a) Innovation and sustainable green growth

In most countries, government procurement has gradually shifted from a limited administrative process to "smart" procurement management, including strategic procurement for innovation. An effective government innovation procurement strategy and the appropriate combination of policies are the most important conditions for implementing innovation procurement and have an important impact on the innovation environment.

(b) Innovation and the development of small and medium enterprises

Almost every member country in OECD has provided some funding support for small and medium enterprises in the policies on innovation or employment. Support for small and medium enterprises to participate in innovation procurement can be direct financial incentives, guarantees, or indirect incentives including encouraging small and medium enterprises to participate in quotations, supplying administrative assistance, providing trainings, and promoting open tenders. For example, in 2004, South Korea began to combine the policy goals of innovation procurement with the development of small and medium enterprises, which has been implemented as a national plan to support innovative small and medium enterprises.

\section{The Enlightenment to China}

Through government procurement to promote technology innovation is an international practice, but China has not fully implemented this measure. China should positively learn from foreign experiences and establish the policies of government procurement to promote technology innovation as soon as possible. At the same time, it is important that the policies to promote technological innovation should be more significant, more complying with international rules, more operational, to ensure a long-lasting effectiveness for the government procurement to promote technology innovation.

\subsection{Restructuring and Improving Government Procurement Policies to Promote Independent Innovation}

Most OECD countries have carried out many practices in the use of government procurement to promote independent innovation, and have developed a series of procurement policies and measures to support technological innovation. Although many countries have joined the GPA, it is not difficult to find that these countries have still successfully 
implemented their support for their high-tech industries through various policies, which have played an important role in promoting technological innovation in these countries.

Therefore, China urgently needs to restore the government procurement policy measures linked to the innovation and provide incentives to play a good role to leverage innovation promotion. China should improve the terms that are easy to cause disputes, and flexibly avoid the constraints of international rules. For example, to use exception clauses in the WTO "Government Procurement Agreement" to protect the procurement of domestic products; to split the contracts or use other methods to make the government procurement contracts lower than the threshold set by the WTO "Government Procurement Agreement"; to use trade compensation mechanisms, which requires that if the foreign suppliers win the bid, they must achieve a certain percentage of domestic purchases, transfer certain technologies or create a certain amount of employment for China.

\subsection{Formulating Operational Rules}

How to lean toward independent innovation products in government procurement practices is an important factor. The government procurement management department should issue detailed rules to support the independent technological innovation products as soon as possible, and ensure that these rules are operational, so that the procurement agencies can effectively lean to the independent innovation products that are qualified in purchase price, quality and technology requirement during the evaluation. For example, the lowest bid can be used. Long-lasting unchanged mode has become the biggest obstacle that must be overcome in innovation procurement practices. In order to promote innovative programs and initiatives, it might be better to use the most economical bidding criteria and measures, and to take the life cycles of the products into the consideration for costs. In addition, when purchasing some products, engineering programs and services in government procurement projects, especially the demonstration major procurement projects, which can stipulate that independent innovation products must account for certain proportion of the total government procurement to achieve the purpose of promoting independent technological innovation, to establish a demonstration effect for market consumption, and to expand the social impact of independent innovation products.

\subsection{Balance Between Innovation Goals and Main Goals}

The main goals of government procurement are usually related to savings and efficiency, to purchase required products in a timely, economical and efficient manner. Therefore, as a secondary goal, innovation needs to keep the balance with the main procurement goals. Purchasers should assess the value in pursuing secondary policy goal based on main goals of public procurement and make a balance evaluation between the potential benefits and actual price. The ability of the purchasers to achieve secondary policy goals and to the burden to monitor of progress towards such goals should also be considered. In the current international and domestic environment, China should pay more attention to the policy function of government procurement to promote technological innovation than ever before, and give greater importance to the innovation elements when evaluating bids.

\subsection{The Target of Government Procurement Extends to the Non-competition Stage}

Incentives for independent innovation through government procurement are not limited to the phase of competition after commercialization, that is, the procurement for final innovative products. OECD countries usually pay more attention to the procurement contracts for $R \& D$ results or test products before commercialization of innovative products, as well as the effective connection between pre-commercial procurement and post-commercial procurement; and the joint use of preferential policies such as direct procurement of products, direct investment in research and development, tax reduction for $R \& D$ investment, and $R \& D$ talent training. The target of government procurement incentives for independent innovation has also been extended from the final innovative product phase to the pre-competition phase, such as new technology procurement, $R \& D$ contract procurement and trial product procurement. This is also more conducive to circumvent the barriers of the Government Procurement Agreement under the WTO framework for the opening procurement of innovative products.

\section{Summary}

According to the experiences of government procurement in OECD countries, nowadays, government procurement is not only a means of financial management, but also an effective tool for the country to implement macroeconomic regulation and control under market economy conditions. It plays a comprehensive role in politics, economy, and society. In the context of China's participation in WTO and the liberalization of world investment and trade, it is particularly necessary to strengthen the awareness of the function of government procurement policies, fully understand the role of government procurement, and make the best of the functions of government procurement to regulate the economy. And according to the different stages of industrial development, combining the measures of R\&D funding, tax reduction, establishment of technical barriers, tariff protection and other policies together to form a systematic and innovative policy system. It is an urgent need under the background of globalization, which has accelerated the development of emerging countries and fostered strategic emerging industries. In such international competitions, the value of the policy implementation and the necessity of policy intervention are obvious. China should learn from the practices of other countries, further understand the role of the government procurement system, improve the policy system, and give full play to the regulatory functions of government procurement. 


\section{References}

[1] WIPO, Cornell University, INSEAD. The Global Innovation Index 2016: Winning with Global Innovation [R]. Ithaca, Fontainebleau, and Geneva, 2016.

[2] Liu Shibai. Promote transformation and stabilize growth through technological innovation [J]. Economist, 2013, 11 (11): $5-13$.

[3] Jiang Dayang. Is public procurement an innovation policy? -Analysis from the EU procurement policy [J]. Journal of Lanzhou University of Finance and Economics, 2010, 26 (3): 85-89.

[4] E Mansfield, M Schwartz, S Wagner. Imitation Costs and Patents: An Empirical Study [J]. Economic Journal, 1981, 91 (364): 907-918.

[5] Economic Development Theory [M]. by Joseph Schumpeter, translated by Zou Jianping. Beijing: China Pictorial Publishing House, 2012.

[6] Porter Michael. The Competitive Advantage of Nations [M]. New York: The Free Press, October 1990.

[7] R Dalpé. Effects of government procurement on industrial innovation [J]. Technology in Society, 1994, 16 (1): 65-83.

[8] Externality, Technological Innovation and Government Role [J]. By Cheng Hua. Exploration of Economic Issues, 2000 (8): 67-69.

[9] Government Behavior Research on the Coordinated Development of Product and Innovation Process in Manufacturing Enterprises [J]. Bi Kexin, LIU Yuhong, SUN Jinhua, China Science and Technology Forum, 2009 (3): 82-87.

[10] The American Recovery and Reinvestment Acts of 2009, SEC1605.

[11] P. A. Geroski. Procurement policy as a tool of industrial policy [J]. International Review of Applied Economics, 1988, 4 (2): $182-198$. 